\title{
An Empirical Investigation on Students' Acceptance of (SM) Use for Teaching and Learning
}

\author{
https://doi.org/10.3991/ijet.v15i04.11660 \\ Ibrahim Youssef Alyoussef \\ King Faisal University, Alahsa, Saudi Arabia \\ ialyoussefekfu.edu.sa
}

\begin{abstract}
The current work aims at developing a model of teaching and learning measurement through using Social Media (SM), incorporating the literature of SM adoption on resource sharing, collaborating and communicating for educational purpose. The current study hypothesizes that perceived usefulness, perceived ease of use, attitude toward use, and SM use have certain influence on adoption of resource sharing, collaboration and communication for educational use. Therefore, resource sharing, collaboration and communication influence educational use, while educational use influences perceived ease of use, perceived usefulness, SM use and attitude toward the use of SM for teaching and learning. A Technology Acceptance Model (TAM) version was utilized in this research to be the main framework. Both the processes of collecting and analysing the data followed the quantitative approach. The main tool of data collection was a survey that has been distributed among 236 students using stratified random sampling technique. The view of the students and their implication of SM use for teaching and learning were solicited through the survey. Structure Equation Modelling (SEM) was used as the main tool in the process of data analysis. The results of this study were related to two main constructs: teaching and learning as well as educational use. According to the results, it appears that perceived usefulness, perceived ease of use, attitude toward use, and SM are considered powerful determinants of the former while resource sharing, collaboration and communication were significant indicators of the latter. Educational use, perceived usefulness, perceived ease of use, attitude toward use succeeded in explaining $65.5 \%$ of SM use for teaching and learning.
\end{abstract}

Keywords-Technology Acceptance Model (TAM), Social Media (SM) Use, Teaching and Learning

\section{Introduction}

The rapid expansion of social media SM has become a key factor for teaching and learning strategy. It is dramatically transforming the way about how our teachers teach their students and how our students learn. This development has given birth to a number of emerging SM tools that are categorized under the name SM. SM tools such as Blog, Wiki, Facebook, Twitter, YouTube, and Virtual world have become 
increasingly powerful, global, interactive, and dynamic tools. They also create, customize, communicate, and share a variety of unique and powerful information via the information and communication technology ICT [1]. SM also helps anyone to collaborate, communicate, and participate with others through the Internet technology (World Wide Web), which realizes the original vision of the Web, as a space [2, 3, 4]. The SM tools have become a trend among the members of the Net generation or digital native who were born and interacted with digital technology [5]. Recently, the various sites of SM are becoming widespread e-learning platforms used for the purpose of knowledge sharing and engagement in active collaborative learning $[6,7$, 8]. The development as the assessment of the finest social connections among learners is becoming possible through these sites. This is leading to more sharing of ideas, interacting and engaging which helps to produce products and to be at the same time recipients themselves of accurate and regular feedback $[9,10]$. For example, SM are becoming the modern classrooms, instead of the traditional ones, in which teaching and learning take place. Through these sites, students can learn languages and other skills [11]. They are also known to enhance students' creativity and skills [12]. Through SM use, exploring, following and replying to other posts by other users became possible for all users. It is also allowing virtual interactions and collaborations among people from different corners of the world $[13,14]$. There are other examples of SM tools such as Pownce, Tumblr, Utterli, Plurk, Jaiku. Yappd, Edmodo, Cirip.ro, Logoree.ro, Zazazoo [15, 16]. The best feature of SM is the allowing for large amount of users to connect to each other in the same time [17]. SM is currently the fastestgrowing technology in the world used by active users among Net generation. According to the global web index site (2013), there were over 554 million active registered SM users in the world at the time that article was published. The majority of these users forming (34\%) are aged between 25 to 34 year olds and (29\%) of them are aged between 16 to 24 years old. More specifically, there are 4 million active users in the Middle East. The majority of these users with a percentage of (34\%) are from Arab countries [18]. The most common purpose of using SM appears to of a personal use. However, others highlighted that they use this technology for communication, learning, knowledge management and interactive journalism. Recently, several studies in the developed countries have focused on the enhancement of teaching and learning via SM $[15,16,19]$. The main aim of this research is to examine the intentions of teachers towards the use of SM as to enhance their teaching and learning activities. However, no studies have investigated the use of SM for teaching and learning in higher education. Therefore, the main purpose of this study was to develop a model to measure teaching and learning through SM use, and incorporate the literature of SM adoption on resource sharing, collaboration and communication for educational purpose.

\section{Theoretical Model}

The theory considered most appropriate and relevant for this study is the Technology Acceptance Model (TAM). TAM was developed to emphasize the design 
of system characteristics. When he developed this model in 1986, Davis [20] sought an approach of using computer technology in various settings [21]. Through adoption, the theory of reasoned action (TRA) was the basis of this model. This theory explains people's behavior through their engagements [22]. TAM divides the TRA's attitude paradigm into two groups: perceived ease of use and perceived usefulness. The two groups explain the behavior that human beings adapt when using technology [21]. TAM model takes into consideration the salient features of SM. The underlying assumption of the TAM model is that organizations use the information to improve workers' effectiveness. Nevertheless, this model overlooked the fact that people could use the information system outside the organizational environment for self-benefits such as entertainment. At the same time, the model fails to consider the economic and environmental factors likely to affect the person inclination towards certain behaviors [23]. Despite the limitation, the TAM model has the potential to help future educators, practitioners, and scholars in the area of SM. TAM revisions have been applied to various technologies. Among these technologies are SM tools [24, 25]. Al-Daihani [26] examined the factors that shape the learners' decision to adopt SM as a source of information. Also, Al-Rahmi et al. [27] the main findings state that students' learning activities can be enhanced through active collaborative learning and engagement via SM. This discussion can be also improved leading to the encouragement of learning and teaching processes within higher education institutions. Both of the researches relied on the improved TAM to probe the factors that sway the decision to be on adoption of SM. Therefore, the current study integrates the relevant factors to resource sharing $(\mathrm{RS})$, communication $(\mathrm{CM})$, collaboration $(\mathrm{CO})$, educational use (EU), perceived usefulness (PU), perceived ease of use (PEU), attitude toward use (AT), and SM use (SMU).

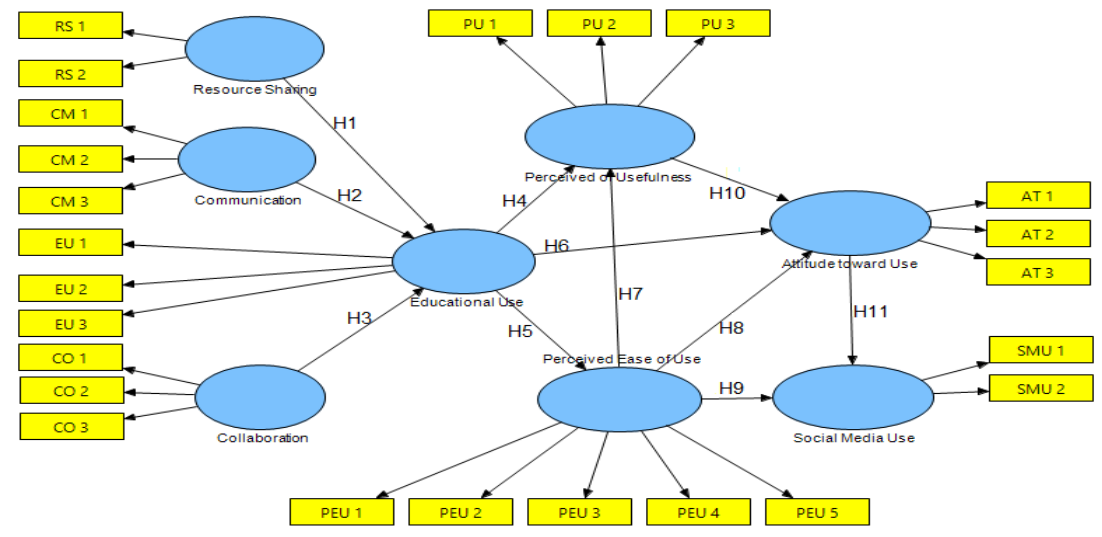

Fig. 1. Research Model

\subsection{Resource sharing (RS)}

Though collaboration and fruitful discussion, universities can go beyond the usual classroom. As they share resources, they are expected to provide their countries with a 
great benefit. An example for that would be anticipating knowledge through the various SM networks [28, 29]. The different ways of communicating with others via knowledge sharing are highlighted by the increasing use of SM [1, 30]. Moreover, the issue of the experience related to the use SM network has been studies by many researchers who found out that there is a significant relationship among collaborative authoring, learning outcomes, experience for collaborative learning, and resource sharing $[31,32,33]$. On the light of the discussion above, the flowing hypothesis was generated to be examined:

H1: RS and EU are significantly related to each other.

\subsection{Communication (CM)}

Through SM, it is noticed that the rate of communication between students and others is rapidly increasing especially in the case of assessment tasks. It has been noted that communication is strongly enhanced by SM [12]. This enhancement involves a more positive learning attitude, a large number of motivated students to learn and to handle tasks carefully and with passion. All of this is expected to raise their social capital through such virtual interactions. Even though, the issue of SM use for the purpose of teaching and learning has been studied by many researchers, still there is a need to investigate this issue in more depth. Basically, these studies suggest that these SM tools can be used as techniques for learning and teaching in higher education due to their networking nature. Learners can communicate with their surrounding communities and among themselves through these tools. Academicians as well can make use of SM tools for communication. The use of Facebook in the interaction between students and researchers and among academicians in general would be a clear example of that [36]. Taking this discussion into consideration, a new hypothesis can be proposed for examination. This hypothesis is mentioned in the flowing:

H2: CM and EU are significantly and closely related.

\subsection{Collaboration $(\mathrm{CO})$}

Recently, it is noticed that the trend followed by higher education in terms to learning became projected towards the skills needed for the life-long-learning rather than the traditional way of seeking knowledge [37]. One of these attractive skills is known as the skills of collaboration which proved to be one of the highly valued skills by employers [38]. In terms of interactivity, it is observed that Web 2.0 - the currently used SM- compared to web 1.0- the previously used type of SM- offers more in terms of interactive communications [39]. This is true as the recent SM enables users to have an active collaborative learning through a variety of tools such as Blogs, Facebook and YouTube. For achieving a significant collaborative learning within higher education through SM, there is a need to have certain skills such as motivation cognitive skills reflection, active collaborative learning and metacognition [40, 41]. The following hypothesis is generated based on what has been discussed above:

H3: CO and EU are significantly related. 


\subsection{Educational Use (EU)}

Many benefits such as validating and appreciating creative work, supporting towards peer alumni are provided to students being SM users. Several factors such as the use of SM in a faculty level [13, 35, 42, 43], the engagement of student [29, 37], SM influence on their academic achievement $[29,37]$ have been studied within the environment of higher education. The results by Yang et al. [44] highlighted that the use of SM has a positive influence of students' peer interaction and academic achievement. Moreover, it shows that the use of SM technologies is still not well used in education. In a similar study, Roblyer et al. [35] observed that the respondents were encouraged to use and utilize the different tools of SM websites within their teaching and learning as compared with the institution that still used the traditional approaches in teaching. Tess [45] emphasized that most of universities and higher educational institutions have the tools and the infrastructure for enabling the use of SM. The researcher further highlighted that the problem is that teachers and lecturers are not adopting this technology as fast as they are supposed to be. The hypotheses below are generated based on this discussion.

H4: There is a significant relationship between EU and PU.

H5: There is a significant relationship between EU and PEU.

H6: There is a significant relationship between EU and AT.

\subsection{Perceived ease of use (PEU)}

The extent to which individuals believe that using a certain system does not need much effort is known as Perceived ease [20]. TAM is deemed a flexible model as it includes variables which can explain technology acceptance [46]. In a more detailed definition, this term has been used to highlight the easiness of a certain system to users. This easiness involves the mental effort needed to interact with the system [47]. Technology acceptance, according to the findings of previous related research, can be strongly predicted by PEOU [48, 46]. Similarly, studies have not found a clear-cult evidence that technology can be significantly influenced by perceived ease of use [49, 8]. The following hypotheses are proposed based on the above discussion:

H7: There is a significant relationship between PEU and PU.

H8: There is a significant relationship between PEU and AT.

H9: There is a significant relationship between PEU and SMU.

\subsection{Perceived usefulness (PU)}

It had been proposed by Davis's [20] that certain factors such as perceived usefulness, attitude and perceived ease of use can be the components of TAM. While the positive or negative reactions by individuals towards a certain thing is called attitude [50], the perspectives of individuals of a certain system being useful to them through influencing their performance is called perceived usefulness [20]. [20, 48]. It has been argued by Tan and Teo that technology innovations adoption can be determined and explained by perceived usefulness [49]. According to [51], perceived 
usefulness also refers to the willingness of individuals to manage a particular system. The usefulness and ease of use in terms of individuals' perceptions on technology and SM are some of the characteristics of Users' behaviour [29, 40, 52]. The following hypothesis is proposed based on this discussion above.

H10: PU and AT are significantly related.

\subsection{Attitude toward use (AT)}

The study established that the positive attitude by students towards SM is linked to an increased use of the technology for academic purposes. The authors uncovered the motivation behind the use, interactive nature, pedagogical significance, and theoretical implications [53]. On the same vein, [54] insisted that the attitude towards Facebook by the millennial influences their usage on SM for academic purposes. There is a need to incorporate SM as an indispensable tool in the academic field due to positive perception entrenched in students [55]. The findings guide the academic institution to integrate SM tools while probing new ways of impacting the opinion of the teachers and students [33]. Perception is shaped by individual attitudes. According to Eagly and Chaiken [56], attitudes and perceptions are common psychological tendencies that manifest during the assessment of certain entities. The outcome of the perception is either the positive inclination or negative inclination. In the education setting, the students that have a positive attitude towards certain aspects of learning are likely to prefer those approaches over other methods. Thus, their perception of certain elements of education affects how they shape their behavior towards such elements [57]. Nevertheless, changing perception is possible. Thus, attitude is an inclination that can be altered to improve the students' academic outcome. On the light of the above discussion, the following hypothesis is proposed:

H11: There is a significant relationship between AT and SMU.

\subsection{SM use for teaching and learning (SMU)}

Jamari et al. [58] investigated the students' perception of SM as a learning tool. These researchers employed purposive sampling while distributing questionnaires to the respondents selected from the academic institutions. According to the findings, the flexible gadgets and highly available Internet facilities triggered positive perception towards constant SM use among the students but sometime happen cyber bullying behaviors among students [59]. Therefore, the access of the Internet facilities had a direct influence on their positive perception towards online activities. The students tend to view SM as an alternative platform for academic growth, even though the primary purpose was to socialize people. This perception makes the students associate SM with academic growth. Jamari et al. [58] confirmed this hypothesis by establishing that Facebook is the most preferred SM, followed by Instagram and WhatsApp. Irrespective of the gender, the learners have a positive inclination towards the idea of using SM in the learning process. The findings revealed that 58 percent of learners declined to participate in the teachers' online social platform but still supported the use of the school's page for academic purposes [58]. Notwithstanding 
the positive perception and inclination, there is a need for planning to ensure that the outcomes align with the students' preferences. Neier and Zayer [53] investigated the student experiences and perception towards SM as an educational tool in higher institutions of learning. This study sought to build on the existing studies that have revealed the opportunities linked with SM usage as academic tools in the classroom. Therefore, this research probed the perception which is held by students regarding the importance of SM in improving their academic experience. Students' perception has a significant impact on their behavior. Moongela and McNeil [60] shared this insight by claiming that students tend to spend a lot of time on SM. Equally, it has been noted that both of simplicity and speed are the most attractive qualities of web and webbased SM (big data). Due to these qualities, public sharing of information, engagement, and collaborative learning are becoming the most important features of these sites.

\section{$3 \quad$ Research Methodology}

Totally 236 students volunteered in this study. The survey the primary tool of data collection was given manually to the respondents and was asked to fill them in order to obtain their feedback on SM and how they are used to the purpose of enhancing an active resource sharing, collaboration, communication, educational use and their performance impact for teaching and learning. The survey asked the respondents to answer questions in relation to SM. The use of SM for educational purpose has been encouraged by many universities including King Faisal University (KFU). Thus, the research aims at developing a model of measurement teaching and learning on the use of SM through an empirical investigation on students' acceptance of SM use for teaching and learning. Two (2) experts validated the questionnaire by checking the face and content validation. A quantitative research methodology was used in the study. Undergraduate students using SM tools were asked to complete a 7-point Likert scale questionnaire to measure their "rating of different items". The questionnaire covers three main sets of factors, including the items of independent factors. The items are resource sharing, collaboration, communication and educational use. Responses to the questionnaire were analyzed using Statistical Package for the Social Sciences (SPSS). For the analysis, Hair et al. [63] recommends the use of Structural Equation Modeling (SEM-Smart-PLS) in two main phases. In the first phase, the construct, converge and discriminate the validities of the measurement model are calculated. The second phase examines the structure model.

\subsection{Characteristics of sample and data collection}

236 questionnaires were entered and tabulated to SPSS. In terms of the demographic details of the respondents: 73 respondents forming $(30.9 \%)$ were males, 163 respondents forming $(69.1 \%)$ were females. As for the age of the participants, 164 respondents forming $(69.5 \%)$ were in the age range of $17-22,44$ respondents forming $(18.6 \%)$ were in the age range of $23-28,9$ respondents $(3.8 \%)$ were in the 
age range of $29-34$, and 19 respondents $(8.1 \%)$ were in the age range of 35 - over. Regarding the demographic factors, the frequency of SM used, $102(43.2 \%)$ of the respondents indicated that they use SM several times in a day, 49 (20.8\%) of the respondents utilize SM an once in a day, $25(10.6 \%)$ of the respondents make use of SM several times in a month, $25(10.6 \%)$ of the respondents use SM an once in a month, while $35(14.8 \%)$ of the respondents use SM several times in a year. Regarding the demographic factors regarding the time of SM used per day, 106 $(44.9 \%)$ of the respondents use SM less than 15 min per day, $61(25.8 \%)$ of the study participants make use of SM approximately half an hour per day, 34 (14.4\%) of the respondents use SM approximately an hour per day, and $19(8.1 \%)$ of the respondents use SM one to three hours per day, while $16(6.8 \%)$ of the respondents use SM more than three hours per day.

\subsection{Measurement instruments}

The main purpose of adapting the constructs items was to achieve a satisfactory result regarding content validity. The survey comprises of three main sections. The first section was designed to collect the students' demographic information such as gender and age as well as information about the respondents' frequency of using SM. The second part - adapted from the related literature- was designed to solicit students' views on various constructs namely resource sharing, collaboration, communication, and educational use [1, 2, 61]. The third and final part was also adapted from the studies by $[20,46]$.

\section{$4 \quad$ Result and Analysis}

The reliability of Cronbach's Alpha was analysed and found to be 0.838 of the TAM comprising of PU, PEU and AT the use of SM. It also includes the values on $\mathrm{RS}, \mathrm{CO}, \mathrm{CM}$, and EU that are considered as independent factors. These factors are also known of their strong influence on the use of SM in teaching and learning. The discriminant validity of the five dimensional scales was tested in three criteria. In particular, these criteria were index among variables; the average variance extracted (AVE) value of each construct and should be under 0.80 based on the recommendations by [63], square of (AVE) of every single construct. The resulting value must be 0.50 or above and the value of .The third criteria should be above the inter construct correlations (IC) connected to the factor [88]. According to [63], the resulting values of Cronbach's Alpha (CA) and composite reliability (CR) are expected and should greater than or equal to 0.70 . Both of the factor loading (FL) and crematory factor analysis (CFA) values is tested and should be equal to or above 0.70 .

\subsection{Measurement model and instrumentation}

The use of Partial Least Square was the first step in the model's legitimacy and dependability assertion. Through the use of Basic Equations Modeling (PLS-SEM) 
and Smart PLS 2.0, previous related theories were examined and the integrity fitness of the current model was checked. Similarly, a number of things were determined such as the legitimacy build that ranges the loadings of components; the composite unwavering quality, Cronbach's alpha, and the merging legitimacy. At this point, the study also utilized standard test in order to affirm discriminant legitimacy following the recommendations by [64].

\subsection{Construct validity of the measurements}

Develop legitimacy, which is defined as the level to which things used to measure, can calculate the idea they were meant to quantify [63]. All of the items used to measure the develop should pile essentially to their individual develops rather than different builds. This was certain by having an orderly audit of writing in the mission to deliver things that have as of now been set up and tried by earlier writers. As for component analysis, it was ensured that things get to be named to their develop as they expressed high loadings on them which stood out from several develops (See Table 1).

Table 1. Loading and cross-loadings of the items

\begin{tabular}{|c|c|c|c|c|c|c|c|c|c|}
\hline Variables & Code & $\mathbf{A T}$ & CM & $\mathrm{CO}$ & EU & PEU & PU & RS & TU \\
\hline \multirow{3}{*}{ Attitude toward use } & AT 1 & 0.865 & 0.341 & 0.361 & 0.440 & 0.452 & 0.211 & 0.261 & 0.681 \\
\hline & AT 2 & 0.922 & 0.384 & 0.421 & 0.444 & 0.430 & 0.239 & 0.384 & 0.740 \\
\hline & AT 3 & 0.902 & 0.393 & 0.384 & 0.474 & 0.315 & 0.224 & 0.394 & 0.714 \\
\hline \multirow{3}{*}{ Communication } & CM 1 & 0.448 & 0.857 & 0.609 & 0.691 & 0.339 & 0.363 & 0.555 & 0.447 \\
\hline & CM 2 & 0.354 & 0.878 & 0.632 & 0.626 & 0.290 & 0.263 & 0.567 & 0.407 \\
\hline & CM 3 & 0.243 & 0.839 & 0.681 & 0.534 & 0.285 & 0.247 & 0.526 & 0.282 \\
\hline \multirow{3}{*}{ Collaboration } & $\mathrm{CO} 1$ & 0.243 & 0.704 & 0.843 & 0.526 & 0.385 & 0.285 & 0.560 & 0.340 \\
\hline & $\mathrm{CO} 2$ & 0.429 & 0.614 & 0.869 & 0.543 & 0.415 & 0.233 & 0.659 & 0.523 \\
\hline & $\mathrm{CO} 3$ & 0.427 & 0.562 & 0.820 & 0.513 & 0.274 & 0.227 & 0.626 & 0.493 \\
\hline \multirow{3}{*}{ Educational Use } & EU 1 & 0.410 & 0.536 & 0.518 & 0.830 & 0.364 & 0.349 & 0.503 & 0.399 \\
\hline & EU 2 & 0.449 & 0.657 & 0.552 & 0.904 & 0.400 & 0.416 & 0.514 & 0.468 \\
\hline & EU 3 & 0.466 & 0.709 & 0.573 & 0.895 & 0.376 & 0.345 & 0.505 & 0.453 \\
\hline \multirow{5}{*}{$\begin{array}{l}\text { Perceived Ease of } \\
\text { Use }\end{array}$} & PEU1 & 0.270 & 0.274 & 0.303 & 0.340 & 0.727 & 0.504 & 0.247 & 0.332 \\
\hline & PEU2 & 0.345 & 0.350 & 0.410 & 0.357 & 0.761 & 0.358 & 0.347 & 0.367 \\
\hline & PEU3 & 0.293 & 0.260 & 0.333 & 0.319 & 0.795 & 0.374 & 0.242 & 0.327 \\
\hline & PEU4 & 0.409 & 0.226 & 0.284 & 0.298 & 0.824 & 0.365 & 0.244 & 0.431 \\
\hline & PEU5 & 0.436 & 0.307 & 0.361 & 0.401 & 0.858 & 0.385 & 0.276 & 0.471 \\
\hline \multirow{3}{*}{$\begin{array}{l}\text { Perceived } \\
\text { Usefulness }\end{array}$} & PU 1 & 0.193 & 0.275 & 0.270 & 0.330 & 0.447 & 0.863 & 0.283 & 0.214 \\
\hline & PU 2 & 0.208 & 0.309 & 0.217 & 0.366 & 0.444 & 0.850 & 0.260 & 0.255 \\
\hline & PU 3 & 0.193 & 0.219 & 0.206 & 0.297 & 0.258 & 0.616 & 0.123 & 0.151 \\
\hline \multirow{2}{*}{ Resource Sharing } & RS 1 & 0.325 & 0.583 & 0.688 & 0.547 & 0.302 & 0.256 & 0.937 & 0.449 \\
\hline & RS 2 & 0.400 & 0.617 & 0.675 & 0.534 & 0.337 & 0.292 & 0.934 & 0.486 \\
\hline \multirow{2}{*}{ SM Use } & SMU1 & 0.758 & 0.384 & 0.421 & 0.401 & 0.383 & 0.189 & 0.375 & 0.900 \\
\hline & SMU2 & 0.648 & 0.416 & 0.537 & 0.498 & 0.494 & 0.29 & 0.520 & 0.876 \\
\hline
\end{tabular}




\subsection{Convergent validity of the measurements}

The composite reliability is used to estimate the reliability of an instrument. From Table 2, all coefficients were well above 0.60 , indicating that the measurement model scales have adequate and reliable internal consistency. Convergent validity was tested by the method of Hair et al. [63] and Fornell and Larcker [64]. This method is to check whether the Average Variance Extracted (AVE) is greater than 0.50, which means that the variance captured by the corresponding construct is more than the measurement error. Table 2 shows the CFA results of the measurement model. It shows that all AVE values are above 0.50; this indicates that the factors have good convergent validity.

Table 2. Convergent validity

\begin{tabular}{|c|c|c|c|c|c|c|}
\hline Variables & Code & $\begin{array}{l}\text { Factors } \\
\text { Loading }\end{array}$ & $\begin{array}{l}\text { Composite } \\
\text { Reliability }\end{array}$ & $\begin{array}{c}\text { Cronbach's } \\
\text { Alpha }\end{array}$ & AVE & R. Square \\
\hline \multirow{3}{*}{ Attitude toward use } & AT 1 & 0.865 & \multirow{3}{*}{0.924} & \multirow{3}{*}{0.877} & \multirow{3}{*}{0.803} & \multirow{3}{*}{0.322} \\
\hline & AT 2 & 0.922 & & & & \\
\hline & AT 3 & 0.902 & & & & \\
\hline \multirow{3}{*}{ Communication } & CM 1 & 0.857 & \multirow{3}{*}{0.893} & \multirow{3}{*}{0.821} & \multirow{3}{*}{0.735} & \multirow{3}{*}{0.000} \\
\hline & CM 2 & 0.878 & & & & \\
\hline & CM 3 & 0.839 & & & & \\
\hline \multirow{3}{*}{ Collaboration } & $\mathrm{CO} 1$ & 0.843 & \multirow{3}{*}{0.881} & \multirow{3}{*}{0.798} & \multirow{3}{*}{0.712} & \multirow{3}{*}{0.000} \\
\hline & $\mathrm{CO} 2$ & 0.869 & & & & \\
\hline & $\mathrm{CO} 3$ & 0.820 & & & & \\
\hline \multirow{3}{*}{ Educational Use } & EU 1 & 0.830 & \multirow{3}{*}{0.909} & \multirow{3}{*}{0.849} & \multirow{3}{*}{0.769} & \multirow{3}{*}{0.554} \\
\hline & EU 2 & 0.904 & & & & \\
\hline & EU 3 & 0.895 & & & & \\
\hline \multirow{5}{*}{$\begin{array}{l}\text { Perceived Ease of } \\
\text { Use }\end{array}$} & PEU1 & 0.727 & \multirow{5}{*}{0.894} & \multirow{5}{*}{0.852} & \multirow{5}{*}{0.631} & \multirow{5}{*}{0.188} \\
\hline & PEU2 & 0.761 & & & & \\
\hline & PEU3 & 0.795 & & & & \\
\hline & PEU4 & 0.824 & & & & \\
\hline & PEU5 & 0.858 & & & & \\
\hline \multirow{3}{*}{$\begin{array}{l}\text { Perceived } \\
\text { Usefulness }\end{array}$} & PU 1 & 0.863 & \multirow{3}{*}{0.824} & \multirow{3}{*}{0.700} & \multirow{3}{*}{0.615} & \multirow{3}{*}{0.302} \\
\hline & PU 2 & 0.850 & & & & \\
\hline & PU 3 & 0.616 & & & & \\
\hline \multirow{2}{*}{ Resource Sharing } & RS 1 & 0.937 & \multirow{2}{*}{0.933} & \multirow{2}{*}{0.857} & 0875 & (O) \\
\hline & RS 2 & 0.934 & & & $0.8 / 5$ & 0.000 \\
\hline CMa J & SMU1 & 0.900 & 080 & 732 & 0780 & 065 \\
\hline SIM use & SMU2 & 0.876 & 0.882 & 0.133 & 0.188 & 0.055 \\
\hline
\end{tabular}

\subsection{Discriminant validity of measures}

The Discriminant validity is defined as a degree to measuring how a certain idea along with its markers can be different from another idea along with its pointers [65]. The discriminant validity of the eight dimensional scales was tested. According to 
[64], a construct has discriminant validity if the AVE value of a construct is greater than any squared inter-correlation of that construct with another. Table 3 displays the square roots of the AVE values, it shows that as the AVE was found to be above 0.50 which is critical at $\mathrm{p}=0.001[64]$

Table 3. Latent Variable Correlations

\begin{tabular}{|l|c|c|c|c|c|c|c|c|}
\hline \multicolumn{1}{|c|}{ Variables } & AT & CO & CM & EU & PEU & PU & RS & SMU \\
\hline Attitude toward use & 1.000 & & & & & & & \\
\hline Collaboration & 0.434 & 1.000 & & & & & & \\
\hline Communication & 0.416 & 0.743 & 1.000 & & & & & \\
\hline Educational Use & 0.505 & 0.625 & 0.727 & 1.000 & & & & \\
\hline Perceived Ease of Use & 0.446 & 0.425 & 0.357 & 0.434 & 1.000 & & & \\
\hline Perceived of Usefulness & 0.251 & 0.294 & 0.344 & 0.422 & 0.499 & 1.000 & & \\
\hline Resource Sharing & 0.387 & 0.729 & 0.641 & 0.578 & 0.341 & 0.293 & 1.000 & \\
\hline SM Use & 0.794 & 0.536 & 0.449 & 0.503 & 0.490 & 0.269 & 0.500 & 1.000 \\
\hline
\end{tabular}

\subsection{Analysis of the structural model}

The following stride illustrates the testing of the estimated relations among the figures. Smart PLS 2.0 was used at this point where the model was examined through calculation using the PLS. Then, the coefficient figures were calculated and then illustrated in Figure 2. Figures 3 what's more, show the theories on table 4.

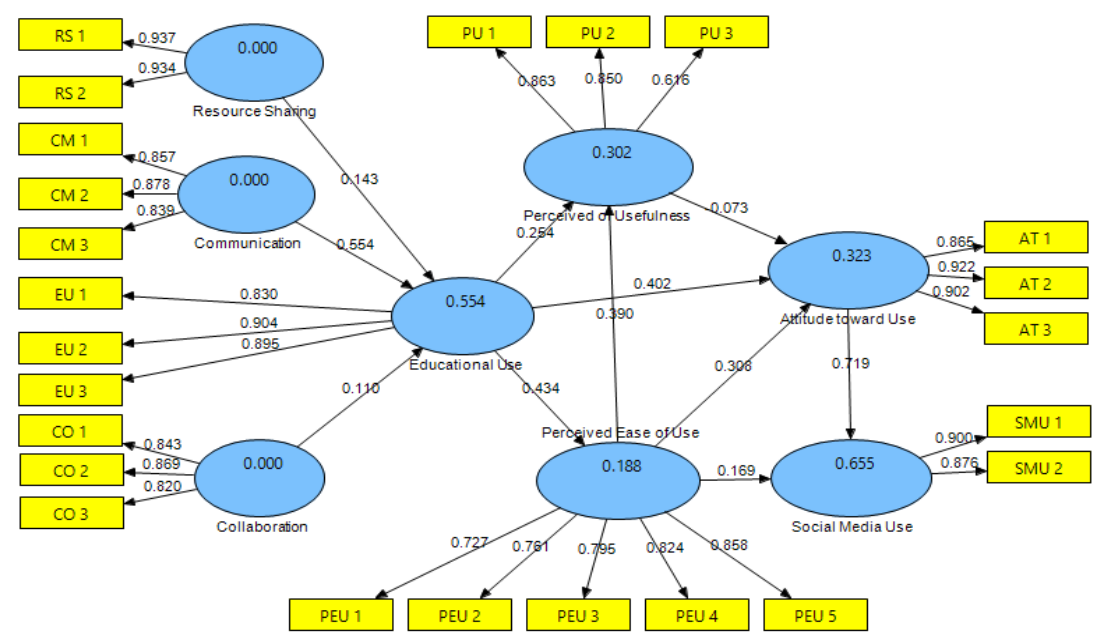

Fig. 2. Path Coefficients Results 


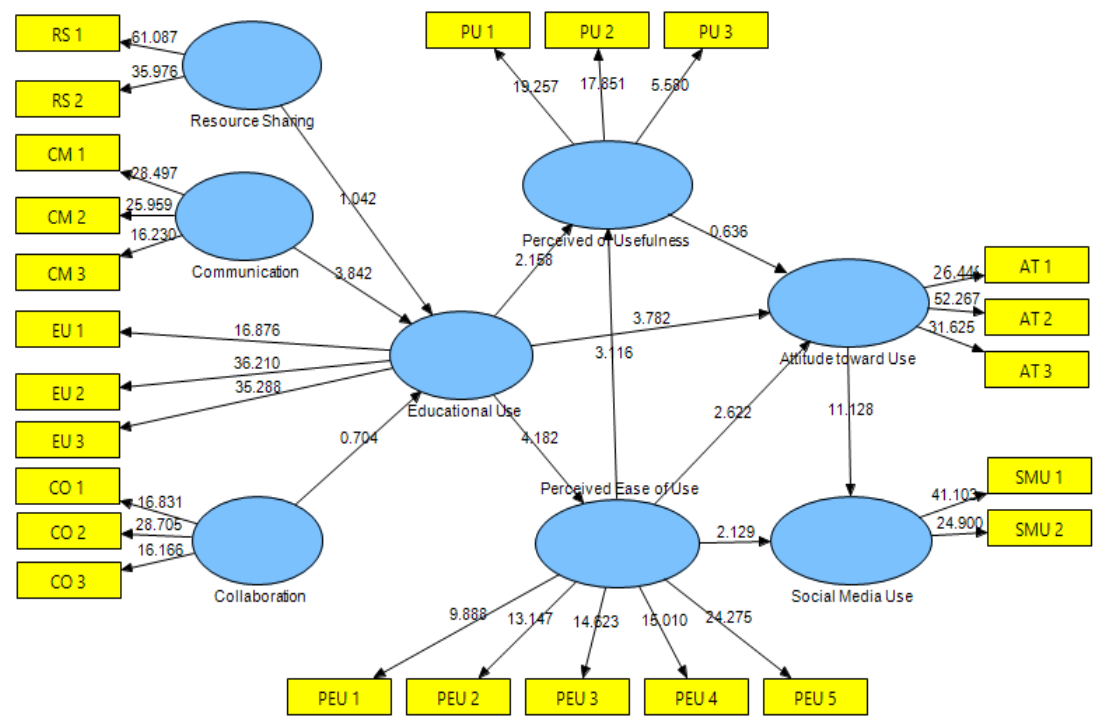

Fig. 3. Path Coefficients T Values

Table 4. Hypotheses testing

\begin{tabular}{|c|l|l|l|c|c|c|l|}
\hline H & Independent & Relationship & Dependent & $\begin{array}{c}\text { Path } \\
\text { coefficient }\end{array}$ & Standard. E & T Value & Result \\
\hline 1 & SR & $\longrightarrow$ & EU & 0.143 & 0.140 & 1.042 & Supported \\
\hline 2 & CM & $\longrightarrow$ & EU & 0.554 & 0.134 & 3.842 & Supported \\
\hline 3 & CO & $\longrightarrow$ & EU & 0.110 & 0.183 & 0.704 & Supported \\
\hline 4 & EU & $\longrightarrow$ & PU & 0.254 & 0.108 & 2.158 & Supported \\
\hline 5 & EU & $\longrightarrow$ & PEU & 0.434 & 0.106 & 4.182 & Supported \\
\hline 6 & EU & $\longrightarrow$ & AT & 0.402 & 0.115 & 3.782 & Supported \\
\hline 7 & PEU & $\longrightarrow$ & PU & 0.390 & 0.124 & 3.116 & Supported \\
\hline 8 & PEU & $\longrightarrow$ & AT & 0.308 & 0.112 & 2.622 & Supported \\
\hline 9 & PEU & $\longrightarrow$ & SMU & 0.169 & 0.074 & 2.129 & Supported \\
\hline 10 & PU & $\longrightarrow$ & AT & 0.073 & 0.109 & 0.636 & Supported \\
\hline 11 & AT & $\longrightarrow$ & SMU & 0.719 & 0.064 & 11.128 & Supported \\
\hline
\end{tabular}

Regarding the first hypothesis, the relationship between resource sharing and educational use was found as $(\beta=0.143, \mathrm{t}=1.042, \mathrm{p}<0.001)$. Therefore, first hypothesis was significant and supported. The second proposition was positive too, significant and supported, as the analysis indicated a relationship between communication and educational use $(\beta=0.554, \mathrm{t}=3.842, \mathrm{p}<0.001)$. The next hypothesis is relationship between collaboration and educational use $(\beta=0.110, t=$ $0.704, \mathrm{p}<0.001)$. Therefore, the third hypothesis was significant and supported. The fourth hypothesis was positive and supported, as the analysis also indicated a relationship between educational use and perceived usefulness $(\beta=0.254, t=2.158$, $\mathrm{p}<0.001)$. Moreover, hypothesis five was also positive and supported as a significant relationship was found between educational use and perceived ease of use $(\beta=0.434$, 
$\mathrm{t}=4.182, \mathrm{p}<0.001)$. Nonetheless, based to the relationship between educational use and attitude toward use $(\beta=0.402, \mathrm{t}=3.782, \mathrm{p}<0.001)$. Therefore, the results indicated a positive as well as a significant relation as stated in the 6th hypothesis. Moreover, the 7 th hypothesis was also supported as the relation between perceived ease of use and perceived usefulness was positive resulting with a value of $(\beta=0.390, t=3.116$, $\mathrm{p}<0.001)$. In addition, the positive and significant relation found between perceived ease of use and attitude toward use provides a strong support for the 8th hypothesis as the results came out as $(\beta=0.308, \mathrm{t}=2.622, \mathrm{p}<0.001)$. Perceived ease of use and SM use for teaching and learning appeared to be closely and significantly related to one another at $(\beta=0.169, \mathrm{t}=2.129, \mathrm{p}<0.001)$. This provides a strong support for the 9 th hypothesis. Similarly, the 10th and the 11th hypothesis were also supported as the relations between perceived usefulness and attitude towards use with and that between attitude toward use and SM use for teaching and learning were found to be positively significant at $(\beta=0.073, \mathrm{t}=0.636, \mathrm{p}<0.001)$ and $(\beta=0.719, \mathrm{t}=11.128, \mathrm{p}<0.001)$ respectively. The support of the 11 th hypothesis goes in line with some of the previous related research $[6,7,13,23,25,32,35,39,40,61]$.

\subsection{Discussion and implications}

The current study aims at cultivating a new model on how SM adoption through resource sharing, collaboration, communication and educational use with TAM is used to explore the factors affecting the attitude of students towards the use SM within teaching and learning in the institution of higher education. This research was an innovative effort in applying resource sharing, collaboration, communication and educational use into a SM adoption via TAM model. Based on the model proposed, the relationships examined through eleven hypotheses was explored with the resource sharing, collaboration, communication and educational use with TAM "perceived usefulness, perceived ease of use, attitude toward use, and SM use" for teaching and learning. SM site enables users to communicate by sharing short messages incorporating 140 characters $[66,67]$. This form of SM is attracting an increasing number of students that associate with entertainment [68]. SM is combined with the Massive open online courses (MOOCS) for academic purposes [69]. Thus, this approach creates a positive impact on student perception and opinions [70]. Compared to other digital devices (e.g. laptops, mobile phones, and personal computers) the mobile devices with touch screens are by far the most popular among young children and this trend is growing rapidly [71], and mobile devices have various distinctive features which might affects certain pedagogies [72]. Therefore, there is a growing perception that incorporating SM to traditional blogging could positively impact the academic outcome. Consequently, the students get the opportunity to utilize SM for the purpose of bringing new academic information into learning. Thus, the findings revealed that SM has a positive impact on student academic experience. It was found that the adoption and use of SM for teaching and learning is influenced by perceived usefulness, students' attitude, and perceived ease of use. Resource sharing, communication, collaboration, and the use of TAM Model were all factors that influence the decision to adopt SM use in the education process. These factors were 
validated based on the findings of this study. The results are consistent with earlier research and support the premise that SM use in teaching and learning is strongly influenced by perceived usefulness and students' attitude towards ease of use of this technology [23, 25, 39, 40, 43, 61]. Colleges and universities should encourage the use of this technology by their students. Students should understand the benefits of adopting and integrating the technology into their learning which can have positive impact on their teaching and learning practices. The study revealed three empirical pieces of evidence. First, the educational use of SM through resource sharing, communication and collaboration. Second, the perceived usefulness and ease of use, that in turn, affect students' attitude toward use SM. Third, students' attitude toward the use of SM which influences its use for teaching and learning [21, 22, 33, 61].

Theoretical implications of research: The outcomes of this research confirm the potential of SM influence for resource sharing, collaboration, communication, educational use and their performance impact for teaching and learning. The results also revealed that perceived ease of use, perceived usefulness of SM among students' effects positively to their resource sharing, collaboration, communication and educational use, and finally, their performance impact on teaching and learning. In addition, the results also showed that group discussion with peers are important to students and researchers as this could result in quality outcome of the group. Such activities may enable the students to generate ideas and opinions positively in group discussions and during interaction with their lecturers. The examination of resource sharing, collaboration, communication and educational use on learning through SM use by TAM and social constructivism theory was also validated by the outcomes of the study. The overall active resource sharing, collaboration, communication and educational use on teaching and learning through SM improve the learning activities of students and facilitate group discussions. The results indicates the improved performance impact on teaching and learning of postgraduate students and the relationship with their interaction with peers, lecturers, their resource sharing, collaboration, communication and educational use, SM use, perceived usefulness, perceived ease of use, and their attitude toward use SM. The use of SM generates an environment that is indicated by the active resource sharing, collaboration, communication and educational use on teaching and learning which can aid the students to work in groups, to accomplish tasks. Based on the outcomes of this study, the use of SM have shown to effectively develop a positive and a learning conducive environment that is invaluable for the resource sharing, collaboration, communication and educational use on learning, and the teaching experience. This research contributes to the literature by proposing a model that integrates constructivism and TAM-the integration of which verified the effectiveness in understanding the following; a) active resource sharing, collaboration, communication and educational use through SM and its effect on the students' satisfaction in Saudi universities, b) effect of SM use on the performance impact on teaching and learning of students in Saudi universities, and c) SM and other related technologies based theoretical model development. The primary objective of the study was to uncover the influence of SM use on resource sharing, collaboration, communication and educational use on teaching and learning and to show how this contributes in enhancing the students' 
performance impact on teaching and learning. The theory of constructivism is used and utilized to guide this objective. This study proves the positive influence of SM on resource sharing, collaboration, communication and educational use on teaching and learning within the education sector in Saudi higher education. The contribution of this study is not only restricted on the use of constructivism theory in investigating the use of SM, but it also provides insights into this field of research and adds to the body of knowledge. Moreover, combining both TAM and the theory of constructivism is a strong point of this study. This is true because this combination has been rarely used to study how education is influenced by SM addressing resource sharing, collaboration, communication and educational use on teaching and learning in particular. Based on the results of the current research, three implications were generated follows:

- Employing SM in the process of teaching and learning. This includes the role played by supervisors and instructors in supporting students through attending to their questions. Also, the easy process of sharing knowledge will enable the students to enhance their research skills

- Encouraging universities and tertiary educational institutions to teach the students how to make use of SM rather forcing them to do so.

- Realizing that both resources and technology are considered significant for students and they can determine their use of SM within teaching and learning.

\section{$5 \quad$ Conclusion and Future Work}

The findings of this research support the effective teaching and learning through SM use. The findings also showed that resource sharing; collaboration and communication influencing educational use would be positively associated with SM used for teaching and learning. The use of TAM model factors (perceived usefulness and perceived ease of use) in examining attitude toward use and SM use for teaching and learning was supported by the results of this research. Thus, the results of this study to resource sharing, collaboration and communication influence educational use. Finally, proposing a model that has both educational use and TAM model can inform much better results. Looking at the degree of significance that students give to attitude towards the use of SM for teaching and learning, future work needs to consider the development of guidelines for teachers on how to integrate SM within the teaching and learning process in different disciplines. Additionally, views of teachers and other higher education stakeholders should be taken into consideration. Finally, cultural perspectives and the limiting and facilitating factors can enrich the research on how to address SM use in different educational environments and contexts. Moreover, this study suggests certain factors such as enjoyment and motivation among others. The following points summarize recommendations for future research: 
- Investigating the various ways by which students can utilize the SM to enhance resource sharing, collaboration, communication and educational use on teaching and learning.

- Explore the effectiveness of utilizing different tools of SM in resource sharing, collaboration, communication and educational use on teaching and learning and how they contribute to knowledge sharing among its users.

- Examining the effectiveness of using technology in the developing countries and their role in resource sharing, collaboration, communication and educational use on teaching and learning.

\section{Acknowledgement}

The author acknowledges the Deanship of Scientific Research at King Faisal University for the financial support under grant number (186254).

\section{$7 \quad$ References}

[1] Al-Rahmi, W. M., Yahaya, N., Aldraiweesh, A. A., Alamri, M. M., Aljarboa, N. A., Alturki, U., \& Aljeraiwi, A. A. (2019). Integrating technology acceptance model with innovation diffusion theory: An empirical investigation on students' intention to use Elearning systems. IEEE Access, 7, 26797-26809. https://doi.org/10.1 109/access.2019.2899368

[2] Mazman, S., \& Usluel, Y. (2010). Modeling educational usage of Facebook. Computers \& Education, 55(2), 444-453. https://doi.org/10.1016/j.compedu.2010.02.008

[3] Sánchez, R., Cortijo , V., \& Javed, U. (2014). Students' perceptions of facebook for academic purposes.Computers \& Education, 70(1), 138-149. https://doi.org/10.101 6/j.compedu.2013.08.012

[4] Al-Rahmi, W. M., Othman, M. S., \& Yusuf, L. M. (2015). Exploring the factors that affect student satisfaction through using $\mathrm{e}$ learning in Malaysian higher education institutions. Mediterranean Journal of Social Sciences, 6(4), 299 -310. https://doi.org/10.59 01/mjss.2015.v6n4s1p299

[5] Solomon, G., \& Schrum, L. (2007). Web 2.0 new tools, new shcools. (1 ed.). Washington,DC: International Society for Technology in Education (ISTE).

[6] Al-Rahmi, W. M., Alias, N., Othman, M. S., Ahmed, I. A., Zeki, A. M., \& Saged, A. A. (2017). Social Media Use, Collaborative Learning and Students'academic Performance: A Systematic Literature Review Of Theoretical Models. Journal of theoretical \& applied information technology, 95(20), 5399-5414. https://doi.org/10.1080/09720073.2017.1317962

[7] Rau, P. L. P., Gao, Q., \& Ding, Y. (2008). Relationship between the level of intimacy and lurking in online social network services. Computers in Human Behavior, 24(6), 27572770. https://doi.org/10.1016/j.chb.2008.04.001

[8] Al-rahmi, W. M., Othman, M. S., \& Yusuf, L. M. (2015). Using Social Media for research: The role of interactivity, collaborative learning, and engagement on the performance of students in Malaysian post-secondary institutes. Mediterranean Journal of Social Sciences, 6(5), 536. https://doi.org/10.5901/mjss.2015.v6n5s2p536

[9] Greenhow, C. (2011). Online social networks and learning. On the horizon, 19(1), 4-12. 
[10] Al-Rahmi, W., Aldraiweesh, A., Yahaya, N., Kamin, Y. B., \& Zeki, A. M. (2019). Massive Open Online Courses (MOOCs): Data on higher education. Data in brief. (22), 118-125. https://doi.org/10.1016/j.dib.2018.11.139

[11] Blattner, G., \& Fiori, M. (2009). Facebook in the language classroom: Promises and possibilities. International Journal of Instructional Technology and Distance Learning, 6(1), 17-28.

[12] Kabilan, M. K., Ahmad, N., \& Abidin, M. J. Z. (2010). Facebook: An online environment for learning of English in institutions of higher education? The Internet and Higher Education, 13(4), 179-187. https://doi.org/10.1016/j.iheduc.2010.07.003

[13] Chen, B., \& Bryer, T. (2012). Investigating instructional strategies for using Social Media in formal and informal learning. The International Review of Research in Open and Distance Learning, 13(1), 87-104.

[14] Luo, T., \& Gao, F. (2012). Enhancing classroom learning experience by providing structures to microblogging-based activities. Journal of Information Technology Education: Innovations in Practice, 11. https://doi.org/10.28945/1689

[15] Hadian, S., Froese, M. E., \& Sanseverino, M. (2011, June). The Use of Micro-Blogging in the Teaching and Learning Process. In EdMedia+ Innovate Learning (pp. 2451-2456). Association for the Advancement of Computing in Education (AACE).

[16] Luo, T., \& Franklin, T. (2015). Tweeting and blogging: Moving towards education 2.0. International Journal on E-Learning, 14(2), 235-258.

[17] Borau, K., Ullrich, C., Feng, J., \& Shen, R. (2009, August). Microblogging for language learning: Using twitter to train communicative and cultural competence. In International conference on web-based learning (pp. 78-87). Springer, Berlin, Heidelberg. https://doi.org/10.1007/978-3-642-03426-8_10

[18] Jazra, K. (2014, July 01). 15 stats about Social Media in the Middle East that you need to know. Retrieved from http://social4ce.com/blog/2014/07/01/15-stats-you-need-to-knowabout-social-media-in-the-middle-east/ https://doi.org/10.1037/a0038309

[19] Al-rahmi, W. M., Othman, M. S., \& Yusuf, L. M. (2015). The effect of Social Media on researchers' academic performance through collaborative learning in Malaysian higher education. Mediterranean Journal of Social Sciences, 6(4), 193. https://doi.org/10.5 901/mjss.2015.v6n4s1p193

[20] Davis, F. D. (1989). Perceived usefulness, perceived ease of use, and user acceptance of information technology. MIS quarterly, 319-340. https://doi.org/10.2307/249008

[21] Rauniar, R., Rawski, G., Yang B.J. (2014). Technology acceptance model (TAM) and Social Media usage: an empirical study on Facebook. Journal of Enterprise Information Management, 27(1), 6-30 https://doi.org/10.1108/jeim-04-2012-0011

[22] Nasri, W. \& Charfeddine, L. (2012). An exploration of Facebook.com adoption in Tunisia using Technology Acceptance Model (TAM) and Theory of Reasoned Action (TRA). Interdisciplinary Journal of Contemporary Research in Business, 4(5), 948-967.

[23] Amadu, L., Syed Muhammad, S., Mohammed, A.S., \& Lukman, S. (2018). Using technology acceptance model to measure the use of Social Media for collaborative learning in Ghana. Journal of Technology and Science Education, 8(4), 321-336. https://doi.org/10. $\underline{3926 / \text { jotse. } 383}$

[24] Pinho, J.C. \& Soares, A. (2011). Examining the technology acceptance model in the adoption of social networks. Journal of Research in Interactive Marketing 5(2/3), 116-129 https://doi.org/10.1108/17505931111187767

[25] Al-rahmi, W. M., Othman, M. S., \& Yusuf, L. M. (2015). The effectiveness of using elearning in Malaysian higher education: A case study Universiti Teknologi 
Malaysia. Mediterranean Journal of Social Sciences, 6(5), 625. https://doi.org/10.59 01/mjss.2015.v6n5s2p625

[26] Al-Daihani, S.M. (2016). Students' adoption of Twitter as an information source: An exploratory study using the Technology Acceptance Model. Malaysian Journal of Library \& Information Science, 21(3), 57-69. https://doi.org/10.22452/mjlis.vol21no3.4

[27] Al-Rahmi, W. M., Othman, M. S., \& Yusuf, L. M. (2015). Effect of engagement and collaborative learning on satisfaction through the use of social media on Malaysian higher education. Research Journal of Applied Sciences, Engineering and Technology, 9(12), 1132-1142. https://doi.org/10.19026/rjaset.9.2608

[28] Nordin, K (2011).Higher Education in the New Economy: Roadmap of Prospects and Challenges. 15th Malaysian education summit Sunway resort hotel \& spa, minister of higher education Malaysia.

[29] Al-rahmi, W. M., Othman, M. S., \& Yusuf, L. M. (2015). Social Media for collaborative learning and engagement: Adoption framework in higher education institutions in Malaysia. Mediterranean Journal of Social Sciences, 6(3 S1), 246. https://doi.org/10.59 01/mjss.2015.v6n3s1p246

[30] Shirky, C. (2011). Cognitive surplus: How technology makes consumers into collaborators. New York, NY: Penguin Press.

[31] Lockyer, L., and Patterson, J. (2008). Integrating social networking technologies in education: a case study of a formal learning environment. In Proceedings of the 8th IEEE international conference on advanced learning technologies 529-533. https://doi.org/10.1 109/icalt.2008.67

[32] McCarthy, J. (2010). Blended learning environments: Using social networking sites to enhance the first year experience. Australasian Journal of Educational Technology, 26(6), 729-740. https://doi.org/10.14742/ajet.1039

[33] Moafa, F. A., Ahmad, K., Al-Rahmi, W. M., Alias, N., \& Obaid, M. A. M. (2018). Factors for minimizing cyber harassment among university students: Case study in kingdom of saudi arabia (KSA). Journal of Theoretical and Applied Information Technology, 96(6), 1606-1618. https://doi.org/10.14419/ijet.v7i4.15149

[34] Wang, Q., Woo, H. L., Quek, C. L., Yang, Y., and Liu, M. (2012). Using the Facebook group as a learning management system: An exploratory study.British Journal of Educational Technology, 43(3), 428-438. https://doi.org/10.1111/j.14678535.2011.01195.x

[35] Roblyer, D., McDaniel, M., Webb, M., Herman, J., and Witty, V. (2010). Findings on Facebook in higher education: A comparison of college faculty and student uses and perceptions of social networking sites. The Internet and Higher Education, 13(3), 134-140. https://doi.org/10.1016/j.iheduc.2010.03.002

[36] Mack, D., and Head, A. (2007). Electronic Journal of Academic and Special Librarianship Reaching Students with Facebook : Data and Best Practices. 2(2), 1-8.

[37] Junco, R. (2012). The relationship between frequency of Facebook use, participation in Facebook activities, and student engagement. Computers \& Education, 58(1), 162-171. https://doi.org/10.1016/j.compedu.2011.08.004

[38] Johnson, L., Adams, S., and Cummins, M., (2012). NMC horizon report: 2012 higher education edition. Technical report. The New Media Consortium, Austin, Texas.

[39] Kaplan, M., and Haenlein, M. (2010). Users of the world, unite! The challenges and opportunities of SM. Business Horizons, 53(1), 59-68. https://doi.org/10.1016/j.bushor.20 $\underline{09.09 .003}$ 
[40] Al-Rahmi, W. M., Yahaya, N., Alamri, M. M., Aljarboa, N. A., Kamin, Y. B., \& Moafa, F. A. (2018). A model of factors affecting cyber bullying behaviors among university students. IEEE Access, 7, 2978-2985. https://doi.org/10.1109/access.2018.2881292

[41] Anderson, J., \& Rainie, L. (2012). Millennials will benefit and suffer due to their hyperconnected lives. Washington DC, Pew Research Center, 18.

[42] Ajjan, H., and Hartshorne, R. (2008). Investigating faculty decisions to adopt web 2.0 technologies: Theory and empirical tests. The Internet and Higher Education, 11, 71-80. https://doi.org/10.1016/j.iheduc.2008.05.002

[43] Al-Rahmi, W. M., Yahaya, N., Alamri, M. M., Aljarboa, N. A., Kamin, Y. B., \& Saud, M. S. B. (2019). How cyber stalking and cyber bullying affect students' open learning. IEEE Access, 7, 20199-20210. https://doi.org/10.1109/access.2019.2891853

[44] Yang, Y., Wang, Q., Woo, H. L., and Quek, C. L. (2011). Using Facebook for teaching and learning: a review of the literature. International Journal of Continuing Engineering Education and Life-Long Learning, 21(1), 72-86. https://doi.org/10.1 $\underline{\text { 504/ijceell.2011.039695 }}$

[45] Tess, P. A. (2013). The role of social media in higher education classes (real and virtual) A literature review. Computers in Human Behavior, 29, A60-A68. https://doi.org/10.1 $\underline{016 / j . c h b .2012 .12 .032}$

[46] Venkatesh, V., \& Bala, H. (2008). Technology acceptance model 3 and a research agenda on interventions. Decision sciences, 39(2), 273-315. https://doi.org/10.1111/j.15405915.2008.00192.x

[47] Oly Ndubisi, N., \& Jantan, M. (2003). Evaluating IS usage in Malaysian small and medium-sized firms using the technology acceptance model. Logistics information management, 16(6), 440-450. https://doi.org/10.1108/09576050310503411

[48] Esteves, J., \& Curto, J. (2013, January). A risk and benefits behavioral model to assess intentions to adopt big data. In Proceedings of the 10th International Conference on Intellectual Capital, Knowledge Management and Organisational Learning: ICICKM 2013.

[49] Tan, M., \& Teo, T. S. (2000). Factors influencing the adoption of Internet banking. Journal of the Association for information Systems, 1(1), 5.

[50] Fishbein, M., and Ajzen, I. (1975).Belief, Attitude, Intention and Behavior: An Introduction to Theory and Research, Addison-Wesley, Reading, MA, 1975.

[51] Bhattacherjee, A. (2002). Individual trust in online firms: Scale development and initial test. Journal of management information systems, 19(1), 211-241. https://doi.org/10.1080/ $\underline{07421222.2002 .11045715}$

[52] Adams, D. A., Nelson, R. R., \& Todd, P. A. (1992). Perceived usefulness, ease of use, and usage of information technology: A replication. MIS quarterly, 227-247. https://doi.org/ $10.2307 / 249577$

[53] Neier, S. \& Zayer, T. (2015). Students' perceptions and experiences of social media in higher education. Journal of Marketing Education, 37(3), 133-143. https://doi.org/10.1 $177 / 0273475315583748$

[54] Thoo, A.C., Ho, P.H., Muharam, M.F. \& Shan, H.L. (2018). Millennials' attitudes toward Facebook advertising. Journal of Computational and Theoretical Nanoscience, 24(6):38643868. https://doi.org/10.1166/asl.2018.11499

[55] Mahdi, M. (2019). Undergraduate Students' Perceptions toward social media Usage and Academic Performance: A Study from Saudi Arabia. International Journal of Emerging Technologies in Learning, 14(3). https://doi.org/10.3991/ijet.v14i03.9340

[56] Trumbo, C. W. (1999). Heuristic-systematic information processing and risk judgment. Risk Analysis, 19(3), 391-400. https://doi.org/10.1111/j.1539-6924.1999.tb00415.x 
[57] Abi, M.J. (2017). Student attitudes on social media and perception of instructor social media use." (2017). Electronic Theses and Dissertations. Paper 2647. https://doi.org/10.18297/etd/2647

[58] Jamari, D., Mohn Zaid, N., Mohamed, H., \& Abdullah, Z.B. (2017). Learning through social media: Students' perception. Man in India, 97(19), 23-27.

[59] Alamri, M. M. (2019). Students' academic achievement performance and satisfaction in a flipped classroom in Saudi Arabia. International Journal of Technology Enhanced Learning, 11(1), 103-119. https://doi.org/10.1504/ijtel.2019.096786

[60] Moongela, H. \& McNeil, J. (2017). Perceptions of social media on students' academic engagement in tertiary education. Proceedings of the South African Institute of Computer Scientists and Information Technologists, Article No. 23. https://doi.org/10.11 $\underline{45 / 3129416.3129423}$

[61] Alamri, M. M. (2014). Facilitating Students' Higher-Order Thinking through ProblemBased Learning: Working in a Blended Learning Environment in Saudi Arabia.

[62] Al-Rahmi, W. M., Yahaya, N., Aldraiweesh, A. A., Alturki, U., Alamri, M. M., Saud, M. S., Kamin, Y. B., Aljeraiwi, A. A. \& Alhamed, A. O. (2019b). Big Data Adoption and Knowledge Management Sharing: An Empirical Investigation on Their Adoption and Sustainability as a Purpose of Education. IEEE Access, 7, 47245-47258. https://doi.org/10.1109/access.2019.2906668

[63] Hair, J. F., Hollingsworth, C. L., Randolph, A. B., and Chong, A. Y. L (2017). An Updated and Expanded Assessment of PLS-SEM in Information Systems Research. Industrial Management \& Data Systems, 117(3): 442-458. https://doi.org/10.1108/imds-04-2016$\underline{0130}$

[64] Fornell, C., \& Larcker, D. F. (1981). Evaluating structural equation models with unobservable variables and measurement error. Journal of marketing research, 18(1), 3950. https://doi.org/10.1177/002224378101800104

[65] Bagozzi, R. P., Yi, Y., \& Nassen, K. D. (1998). Representation of measurement error in marketing variables: Review of approaches and extension to three-facet designs. Journal of Econometrics, 89(1-2), 393-421. https://doi.org/10.1016/s0304-4076(98)00068-2

[66] DePietro, P. (2013). Microblogging in the classroom. Transforming Education With New Media: Participatory Pedagogy, Interactive Learning, and Web, 435, 73-83

[67] Tang, Y. \& Hew, K.F. (2017). Using Twitter for education: Beneficial or simply a waste of time? Computers \& Education 106, 97-118. https://doi.org/10.10 16/j.compedu.2016.12.004

[68] Johnson, K.A. (2011). The effect of Twitter posts on students' perceptions of instructor credibility. Learning Media and Technology, 36(1), 21-38. https://doi.org/10.1080/1 7439884.2010.534798

[69] Al-Youssef, I. Y. (2015). Student acceptance and use of internet-based distance education in Saudi Electronic University (SEU): A mixed method study (Doctoral dissertation, Ohio University).

[70] Bicen, H. (2014). Student opinions regarding twitter usage with mobile applications for educational purposes. Procedia - Social and Behavioral Sciences, 136, 385-390. https://doi. org/10.1016/j.sbspro.2014.05.345

[71] Papadakis, S., \& Kalogiannakis, M. (2017). Mobile educational applications for children: what educators and parents need to know. International Journal of Mobile Learning and Organisation, 11(3), 256-277. https://doi.org/10.1504/ijmlo.2017.085338

[72] Papadakis, S. (2018). Evaluating pre-service teachers' acceptance of mobile devices with regards to their age and gender: a case study in Greece. International Journal of Mobile Learning and Organisation, 12(4), 336-352. https://doi.org/10.1504/ijmlo.2018.095130 


\section{Author}

Dr. Ibrahim Youssef Alyoussef is an assistant professor in Educational Technology department and Vice Dean of students' affairs at King Faisal University, Alahsa, Saudi Arabia. He had his PhD and Master degree in Education Technology from Ohio University, USA, in 2015. He also had his Bachelor degree in Mathematics Education from King Faisal University, SA, in 2001. His research interests include tegration of technology through curriculum development for face-to-face and online learning, the development of virtual learning environments and e-learning; mobile technologies in the classroom, SM Networks, Online course design.

Article submitted 2019-09-11. Resubmitted 2019-11-18. Final acceptance 2019-11-18. Final version published as submitted by the authors. 